\title{
Malarial Infection in HIV Infected Pregnant Women Attending a Rural Antenatal Clinic in Nigeria
}

\author{
R. S. Houmsou, ${ }^{1}$ B. E. Wama, ${ }^{1}$ S. O. Elkanah, ${ }^{1}$ L. C. Garba, ${ }^{1}$ \\ T. D. Hile, ${ }^{2}$ J. B. Bingbeng, ${ }^{3}$ S. L. Kela, ${ }^{4}$ and E. U. Amuta ${ }^{5}$ \\ ${ }^{1}$ Department of Biological Sciences, Taraba State University, Jalingo, Taraba State, Nigeria \\ ${ }^{2}$ Higher Institute of Health Sciences, Adventist Cosendai University, Nanga Eboko, Cameroon \\ ${ }^{3}$ Department of Biology, College of Education, Zing, Taraba State, Nigeria \\ ${ }^{4}$ Department of Biological Sciences, Federal University Kashere, Gombe State, Nigeria \\ ${ }^{5}$ Department of Biological Sciences, University of Agriculture, Makurdi, Benué State, Nigeria
}

Correspondence should be addressed to R. S. Houmsou; rs.houmsou@gmail.com

Received 2 May 2014; Accepted 24 June 2014; Published 17 July 2014

Academic Editor: Chi-Yung Shang

Copyright (C) 2014 R. S. Houmsou et al. This is an open access article distributed under the Creative Commons Attribution License, which permits unrestricted use, distribution, and reproduction in any medium, provided the original work is properly cited.

\begin{abstract}
Malaria still remains a challenging infection affecting the lives of several HIV infected pregnant women in sub-Saharan Africa. This study was undertaken to determine malarial infection in HIV infected pregnant women in relation to sociodemographic and obstetrical factors. The study also assessed relationship between malarial infection and haemoglobin level, $\mathrm{CD}_{4}{ }^{+}$counts, and ART regimen, as well as predisposing risk factors that influenced occurrence of malarial infection in the women. Thick and thin blood smears were prepared and stained with Giemsa. Haemoglobin level was determined using a hematology analyzer, while the flow cytometry was used to measure $\mathrm{CD}_{4}{ }^{+}$counts. Sociodemographic and obstetrical parameters were obtained through the administration of questionnaires. Of the $159 \mathrm{HIV}$ infected pregnant women examined, 33.3\% (59/159) had malarial infection. Malarial infection was significantly higher in pregnant women who were divorced, $40.24 \%(33 / 82)\left(\chi^{2}=5.72 ; P=0.05\right)$, were at their first trimester (4-12 weeks), 54.8\% (17/31) $\left(\chi^{2}=14.85 ; P=0.01\right)$, had $\mathrm{CD}_{4}^{+}=[201-500$ cells $/ \mu \mathrm{L}], 42.42 \%(42 / 99)$ $\left(\chi^{2}=10.13 ; P=0.00\right)$, and those that had severe anaemia $(<8 \mathrm{dg} / \mathrm{L}), 100.00 \%\left(\chi^{2}=45.75 ; P=0.00\right)$. However, risk factors that influenced the occurrence of malarial infection in the pregnant women were occupation (farming) $(\mathrm{AOR}=0.226 ; P=0.03)$, marital status (divorced) ( $\mathrm{AOR}=2.80 ; P=0.02$ ), gestation (first trimester) (AOR $=0.33 ; P=0.00)$, haemoglobin level $(\mathrm{Hb}<$ $8 \mathrm{dg} / \mathrm{L})(\mathrm{AOR}=0.02 ; P=0.00)$, and $\mathrm{CD}_{4}^{+}$counts $\left(\right.$low $\left.\mathrm{CD}_{4}^{+}\right)(\mathrm{OR}=0.40 ; P=0.05)$. The study reported endemicity of malaria in HIV infected pregnant women living in rural areas of Benue State, Nigeria. Malarial infection was higher in women that were divorced, and at their first trimester, had low $\mathrm{CD}_{4}{ }^{+}$count, and had severe anaemia. Farming, divorce, gestation, severe anaemia, and low $\mathrm{CD}_{4}{ }^{+}$counts were predisposing risk factors that influenced malaria occurrence in the HIV infected pregnant women. It is advocated that HIV infected pregnant women should be properly and thoroughly educated on malaria preventive measures in rural areas so as to avoid unpleasant effect of malaria during their pregnancies.
\end{abstract}

\section{Introduction}

Malaria still remains a challenging infection affecting the lives of several HIV infected pregnant women in sub-Saharan Africa (SSA). At least 25 million pregnant women in malaria stable transmission areas of SSA are exposed to Plasmodium falciparum malaria each year [1]. However, HIV infection ranges from $10 \%$ to $40 \%$ and accounts for $10 \%-27 \%$ of malaria in pregnancy [2-4]. HIV infection has been known to augment the risks of placental and peripheral malaria, high density parasitaemia, and febrile malaria illness among pregnant women [3-6]. These women are also at an increased risk of having premature delivery, severe anaemia, delivery of low birth weight babies, and maternal death as a result of frequent and severe malarial infections [4].

In Nigeria, malaria and HIV are serious life threatening problems besides noncommunicable diseases that are on the rise among populations. It is estimated that 3.3 million 
individuals live with HIV/AIDS and over 100 million malaria cases are being reported yearly [7, 8]. From these numbers, 215,000 and 300,000 individuals, respectively, die every year from both diseases with pregnant women seriously affected despite limited data from previous studies.

In Benue State, Nigeria, pregnant women and their unborn babies are exposed to the risk of getting infected with malaria and HIV as both diseases overlap in the area. Malaria transmission is found to be stable [9-12] and HIV has been consistently on the rise from $10.5 \%$ in 2005 to $12.7 \%$ in 2010 [13] making the State to have the highest prevalence in the country.

Previous epidemiological and biomedical studies conducted on pregnant women tended to be characterized by a single disease approach. However, HIV-infected pregnant women who are already faced with poverty, discrimination, and other forms of violence in rural areas remain an understudied group. They are at heightened risk of malaria, HIV/AIDS, and various infectious diseases. They are not also provided with adequate health care services mostly due to poor health infrastructures with limited manpower and underequipped laboratory facilities. At present, there is a dearth of comprehensive epidemiological studies on malarial infection in HIV-infected pregnant women living in rural Nigeria. However, none has been reported in Benue State, Nigeria; thus we carried out this study to determine malarial infection in relation to sociodemographic and obstetrical factors of HIV-infected pregnant women attending antenatal clinic of a rural hospital in Benue State, Nigeria. The study also assessed malarial infection in relation to $\mathrm{CD}_{4}{ }^{+}$counts, haemoglobin level, and ART regimen, as well as risk factors predisposing HIV-infected pregnant women to malaria.

\section{Materials and Methods}

2.1. Study Site. The study was conducted at the antenatal clinic of the General Hospital Vandeikya, Vandeikya LGA, Benue State, central Nigeria. The area is located within the guinea zone savanna of central Nigeria where malaria is perennial but increases during the rainy season (AprilOctober) when mosquito breeding is high [10]. The hospital provides antenatal services and has a well-established HIV care and treatment unit supported by the Centre for Integrated Health Programs (CIHP) a nongovernmental organization. The centre has a flow cytometer where HIV-infected patients get $\mathrm{CD}_{4}{ }^{+}$count measurements. All the pregnant women at the 2nd and 3rd trimesters were administered Sulfadoxine-Pyrimethamine (SP) but not cotrimoxazole as an intermittent preventive treatment.

2.2. Study Population, Inclusion and Exclusion Criteria, and Data Collection. This was a cross-sectional study conducted between June and October 2013. Prior to the commencement of the study, ethical approval was given by the Ministry of Health, Benue State. Management of the General Hospital Vandeikya, Vandeikya LGA, granted us permission to conduct the study. All pregnant women were briefed on the significance of the study and they consented before enrolment.
The study enrolled HIV-infected pregnant women attending routine antenatal services of the hospital. Pregnant women with at least 16 years of age and with gestation of at least 4 weeks were enrolled for the study. Women less than 20 years of age required additional consent from their guardians. Pregnant women with immediate life-threatening medical and obstetrical conditions were excluded.

Following enrolment, a structured questionnaire was administered to each pregnant woman to collect sociodemographic and obstetrical (gestation and gravidity) data. Thereafter, blood samples were collected for HIV and malaria screening, respectively.

\subsection{Laboratory Tests}

2.3.1. HIV Screening and $\mathrm{CD}_{4}^{+}$Counts. About $4 \mathrm{~mL}$ of blood sample was collected into a vacutainer tube from each enrolled pregnant woman. Each tube was appropriately labeled and immediately sent for HIV screening and malaria parasitaemia, respectively. Pregnant women were screened for HIV using the Alere Determine HIV-1/2 rapid immunoassay test strip. Positive samples were confirmed using the Trinity Unigold HIV-1/2 kit (Trinity Biotech PLC, Ireland). The PARTEC cyflow counter version 2.4 (Flow cytometry) was used to count $\mathrm{CD}_{4}{ }^{+}$lymphocytes subsets of the HIVinfected pregnant women.

2.3.2. Malaria Microscopy. Thick and thin blood smears were prepared and stained with Giemsa for light microscopy [14]. Two independent laboratory technicians examined the stained slides for malaria parasites using oil immersion at X100 objective lens. All the positive slides reported Plasmodium falciparum parasite species.

2.3.3. Determination of Haemoglobin $(\mathrm{Hb})$ Concentration. Anaemia was defined as haemoglobin concentration $<11 \mathrm{~g} / \mathrm{dL}$ [15]. Blood samples from the enrolled pregnant women were mixed for 15 minutes in tubes on a haematology mixer; each tube was then transferred to an abacus junior haematology analyzer to determine haemoglobin concentration. Anaemia was categorized as severe $(\mathrm{Hb}<8 \mathrm{~g} / \mathrm{dL})$, mild $(\mathrm{Hb}=8.1-$ $10.9 \mathrm{~g} / \mathrm{dL})$, and normal $(\mathrm{Hb}>11 \mathrm{~g} / \mathrm{dL})$.

2.4. Statistical Analysis. Collected data were entered into Excel 2007 worksheet and imported into SPSS version 19.0 for Windows. The chi-square test was used to compare malaria occurrence between sociodemographic variables, while the logistic regression was used to find association between risk factors that could influence malarial occurrence in HIV infected pregnant women. The adjusted odd ratios with $95 \%$ confidence interval were used to measure the strength of associations. All tests were 2 -tailed and $P$ values less than 0.05 were considered statistically significant.

\section{Results}

Table 1 describes malarial infection in relation to sociodemographic and obstetrical parameters of HIV-infected pregnant women attending a rural antenatal clinic in Nigeria. Malarial 
TABLE 1: Univariate and multivariate analysis of malarial infection in relation to sociodemographic and obstetrical factors of HIV infected pregnant women attending a rural antenatal clinic in Nigeria.

\begin{tabular}{|c|c|c|c|c|c|c|}
\hline \multicolumn{7}{|c|}{ Malaria in HIV-infected pregnant women } \\
\hline Parameters & Examined & Positive (\%) & $x^{2}$ & $P$ & $\operatorname{AOR}(95 \%, C I)$ & $P$ \\
\hline Prevalence & 159 & $53(33.33)$ & & & & \\
\hline \multicolumn{7}{|l|}{ Sociodemographic } \\
\hline Age & & & 3.51 & 0.47 & $1.02(0.60-1.74)$ & 0.92 \\
\hline$[16-20]$ & 26 & $6(23.07)$ & & & & \\
\hline$[21-25]$ & 43 & $12(27.90)$ & & & & \\
\hline$[26-30]$ & 59 & $24(40.67)$ & & & & \\
\hline$[31-35]$ & 24 & $8(33.33)$ & & & & \\
\hline$[36-40]$ & 7 & $3(42.85)$ & & & & \\
\hline Education & & & 0.50 & 0.91 & $1.04(0.51-2.14)$ & 0.00 \\
\hline No formal education & 24 & $9(37.50)$ & & & & \\
\hline Primary & 84 & $27(32.14)$ & & & & \\
\hline Secondary & 51 & $17(33.33)$ & & & & \\
\hline Occupation & & & 3.08 & 0.21 & $0.26(0.08-0.87)$ & 0.02 \\
\hline Trading & 57 & $14(24.56)$ & & & & \\
\hline Farming & 102 & $39(38.23)$ & & & & \\
\hline Marital status & & & 5.72 & 0.05 & $2.80(1.18-6.64)$ & 0.02 \\
\hline Single & 53 & $11(20.75)$ & & & & \\
\hline Married & 24 & $9(37.50)$ & & & & \\
\hline Divorced & 82 & $33(40.24)$ & & & & \\
\hline \multicolumn{7}{|l|}{ Obstetrical } \\
\hline Gravidity & & & 1.63 & 0.44 & $0.98(0.48-2.03)$ & 0.97 \\
\hline Primigravidae & 23 & $5(21.73)$ & & & & \\
\hline Multigravidae & 136 & $48(35.29)$ & & & & \\
\hline Gestation (weeks) & & & 14.85 & 0.01 & $0.32(0.17-0.62)$ & 0.00 \\
\hline$[4-12]$ & 31 & $17(54.83)$ & & & & \\
\hline$[13-24]$ & 79 & $29(36.70)$ & & & & \\
\hline [25-36] & 49 & $7(14.28)$ & & & & \\
\hline
\end{tabular}

Key: $\mathrm{AOR}=$ adjusted odd ratio.

infection was $33.33 \%$ (53/159) among the HIV-infected pregnant women examined. Age-related infection varied between $23.07 \%$ and $42.85 \%$ with no significant difference $\left(\chi^{2}=3.51\right.$; $P=0.47)$. With regard to education and occupation of the women, malarial infection varied between $33.33 \%$ and $37.50 \%\left(\chi^{2}=0.50 ; P=0.91\right)$ and between $24.56 \%$ and $38.23 \%\left(\chi^{2}=3.08 ; P=0.21\right)$, respectively; while in relation to marital status, divorcees were more significantly infected, $40.24 \%$ (33/82), than the singles, $20.75 \%(11 / 53)$, and married, $37.50 \%(9 / 24)\left(\chi^{2}=5.72 ; P=0.05\right)$. In relation to obstetrical parameters, malarial infection did not significantly vary with gravidity though multigravidae had higher infection, $35.29 \%$ (48/136), than the primigravidae, $21.73 \%(5 / 23)\left(\chi^{2}=1.63, P=\right.$ $0.44)$. However, malarial infection was significantly higher in HIV-infected pregnant women at their first trimester (412 weeks $) 54.83 \%(17 / 31)\left(\chi^{2}=14.85, P=0.01\right)$. The sociodemographic and obstetrical risk factors predisposing HIV pregnant women to malarial infection in Vandeikya are occupation (farming) (AOR: 0.26, CI (0.08-0.87), $P=0.02$ ), marital status (Divorce) (AOR: 2.80, CI (1.18-6.64), $P=$ $0.02)$, and gestational age (1st trimester) $(\mathrm{AOR}=0.32, \mathrm{CI}$ $(0.17-0.62), P=0.00)$.
Table 2 shows malarial infection in relation to $\mathrm{CD}_{4}^{+}$ counts, haemoglobin level, and antiretroviral treatment regimen of the HIV-infected pregnant women. A significant malarial infection was observed in pregnant women with $\mathrm{CD}_{4}{ }^{+}$counts $[201-500]$ cells $/ \mu \mathrm{L},(42.42 \%, 42 / 99)\left(\chi^{2}=10.13\right.$; $P=0.00)$ and haemoglobin level $(\mathrm{Hb})<8 \mathrm{~g} / \mathrm{dL},(100 \%$, 19/19) $\left(\chi^{2}=45.75 ; P=0.00\right)$. Women on Pre-ART treatment had higher malarial infection $(37.50 \%, 30 / 80)$ than those on ART $(29.11 \%, 23 / 79)$ with no significant difference $\left(\chi^{2}=1.25\right.$, $P=0.26)$. Low $\mathrm{CD}_{4}{ }^{+}$counts $(201-500$ cells $/ \mu \mathrm{L})(\mathrm{AOR}=$ 0.40 , CI (0.16-1.00), $P=0.05)$ and haemoglobin level $(\mathrm{Hb}<$ $8 \mathrm{~g} / \mathrm{dL})(\mathrm{AOR}=0.02, \mathrm{CI}(0.00-0.17), P=0.00)$ were observed to be malaria predisposing risk factors in the HIV-infected pregnant women.

\section{Discussion}

Malaria and HIV are dreadful infections that affect pregnant women in areas where both infections overlap. In pregnancy, HIV has been hypothesized to impede the development of antimalaria antibodies, therefore predisposing pregnant women at increased risk of developing malaria; on the other 
TABLE 2: Univariate and multivariate analysis of malarial infection in relation to $\mathrm{CD}_{4}{ }^{+}$counts, haemoglobin level, and $\mathrm{ART}$ regimen of $\mathrm{HIV}$ infected pregnant women attending rural antenatal clinic in Nigeria.

\begin{tabular}{|c|c|c|c|c|c|c|}
\hline \multicolumn{7}{|c|}{ Malaria in HIV-infected pregnant women } \\
\hline Parameters & Examined & Positive (\%) & $\chi^{2}$ & $P$ & $\operatorname{AOR}(95 \%, C I)$ & $P$ \\
\hline $\mathrm{CD}_{4}^{+}$count $(\operatorname{cell} / \mu \mathrm{L})$ & & & 10.13 & 0.00 & $0.40(0.16-1.00)$ & 0.05 \\
\hline$[201-500]$ & 99 & $42(42.42)$ & & & & \\
\hline$[501-800]$ & 50 & $10(20.00)$ & & & & \\
\hline$[801-1100]$ & 10 & $1(10.00)$ & & & & \\
\hline Haemoglobin (dg/L) & & & 45.75 & 0.00 & $0.02(0.00-0.16)$ & 0.00 \\
\hline$<8$ (severe anaemia) & 19 & $19(100.00)$ & & & & \\
\hline 8.1-10.9 (mild anaemia) & 140 & $34(24.28)$ & & & & \\
\hline >11 (normal anaemia) & 0 & $0(0.00)$ & & & & \\
\hline ART regimen & & & 1.25 & 0.26 & $0.90(0.35-2.31)$ & 0.83 \\
\hline Pre-ART & 80 & $30(37.50)$ & & & & \\
\hline On ART & 79 & $23(29.11)$ & & & & \\
\hline
\end{tabular}

Key: $\mathrm{AOR}=$ adjusted odd ratio.

hand, malaria could increase HIV mother to child transmission. The present study reports endemicity of malaria among HIV pregnant women in Vandeikya though infection level $(33.33 \%)$ was below $50.00 \%$ as one would have expected the disease to be higher among rural HIV-infected pregnant women living in stable transmission area. The reduced prevalence among these women is the effort of the HIV unit established by the Centre for the Integrated Health Programs (a nongovernmental organization) into the General Hospital to care and treat HIV-infected patients. Pregnant women attending antenatal clinic of the hospital are thoroughly screened for both malaria and HIV and followed up for HIV until delivery and afterwards. Though being vulnerable to malaria because of their weak immune status and rural area of residence, this malaria prevalence is encouraging and found to be lower than $47.70 \%$ observed among HIV-infected pregnant women in Lagos, South West, Nigeria [16]. The malarial infection level found in this study is higher than $5.50 \%$ and $8.00 \%$ reported in Malawian and Rwandan HIVinfected pregnant women $[17,18]$.

Malarial infection did not significantly vary between age groups, education, and occupation of the women. This clearly shows that regardless of their sociodemographic characteristics women living in rural areas are all exposed to infections mostly because they have the same behavioural habits and living conditions. The increased malarial infection among the divorcees might be likely the exposure of these women to mosquito bites through their various occupations as most of them were either farmers or traders. However, the attitudes of not sleeping under bed nets might have greatly influenced malaria rise among these divorcees. This attitude was also observed among pregnant women in neighbouring Gboko Local Government Area who believed that bed nets are used to protect dead bodies from flies [9].

The higher malarial infection in the multigravidae might be likely due to the low level of antibodies against variant surface antigens (VSA) on infected erythrocytes binding chondroitin surface A (CSA) thought to be protecting against placental malaria in HIV seropositive multigravidae pregnant women $[19,20]$. The observed high malarial infection in these multigravidae is equivocal because in many stable malaria transmission areas malarial infection has been reported to be decreasing in HIV-negative multigravidae due to their immune build-up after several pregnancies and infections. Our finding corroborates the fact that HIV infection increases the risk of developing malaria in pregnant women irrespective of their gravidities.

Our study revealed that first trimester of pregnancy (4-12 weeks) is associated and found to be a risk factor predisposing the HIV-infected women to malaria as they were three times more exposed to malaria than women in other gestational ages. This shows that women at that stage of pregnancy were coming for their first antenatal clinic and were yet to be administered sulfadoxine-pyrimethamine (SP) used as the intermittent preventive treatment (IPT) advocated to start only with women at their second and third trimesters. However, pregnant women with low $\mathrm{CD}_{4}{ }^{+}$counts (201500 cells $/ \mu \mathrm{L}$ ) were significantly and four times more infected than those with higher $\mathrm{CD}_{4}{ }^{+}$counts. Pregnant women in this category had most of their $\mathrm{CD}_{4}{ }^{+}$lymphocytes depleted by the virus thereby reducing the production of malaria antibodies. Conversely, the low malarial infection observed in those having higher $\mathrm{CD}_{4}^{+}$count cells could be the reconstitution of their immune system due to the intake of highly active antiretroviral therapy (HAART) or they were newly infected women that still have strong immune system.

Malaria has been associated with severe and moderate anaemia in our HIV cohort. We cannot be conclusive about this because the causes of anaemia in HIV infected individuals are multifactorial. We did not take into consideration other HIV opportunistic infections that cause anaemia such as hookworm infection, schistosomiasis, and diarrheal diseases which are more common in HIV patients. However, the rural residence of these women might have also played a big role, because most of them might not have adequate information about nutritional diet and other factors that could cause anaemia.

Pregnant women on ART were less infected with malarial infection. This corroborates previous studies that reported reduced malarial infection in Nigerian and Ugandan HIV 
patients on ART [21, 22]. However, Skinner-Adams et al. [23] hypothesized the inhibition of malaria parasite growth by certain active compounds like the protease inhibitors found in the HAART drugs.

Our study had various limitations. The cross-sectional nature of the study allowed us to collect only one blood sample for malaria detection. The financial and laboratory constraints did not allow us to carry out real time polymerase chain reaction technique (RT-PCR) which would have reported submicroscopic malaria infections than the light microscopy. The short duration of the study (5 months) was a limitation to assess the malaria effects on the birth weight of new born babies of HIV-infected pregnant women.

In conclusion, our study is the first epidemiological study reporting endemicity of malaria in HIV-infected pregnant women living in a malaria rural stable transmission zone of Benue State, central Nigeria. We found that sociodemographic (occupation, marital status), obstetrical (gestation), and haematological (anaemia and low $\mathrm{CD}_{4}{ }^{+}$counts) factors have been reported to predispose $\mathrm{HIV}$-infected pregnant women to malaria risk. It is therefore recommended that:

(i) HIV infected pregnant women at their first trimester should be administered sulfadoxine-pyrimethamine (SP) as their counterparts at second and third trimesters or they should be given daily cotrimoxazole which is found to be effective for malaria prophylaxis in HIV patients.

(ii) Iron deficiency, the primary cause of anaemia, should be screened properly and pregnant women should be treated promptly so as to curb anaemia known as complication from both malaria and HIV in pregnancy.

(iii) HIV infected pregnant women should be properly and thoroughly educated on malaria preventive measures in rural areas so as to avoid unpleasant effect of malaria during their pregnancies.

(iv) Health nongovernmental organizations should have a memorandum of understanding (MoU) with both public and private hospitals which are already underfunded and neglected by the stakeholders in rural areas. These NGOs can help plan effective screening and control programmes of both malaria and HIV infections and subsequent HIV care follow-up in pregnant women.

\section{Conflict of Interests}

The authors declare that there is no conflict of interests regarding the publication of this paper.

\section{Authors' Contribution}

R. S. Houmsou, S. L. Kela, and E. U. Amuta designed the study. R. S. Houmsou carried out statistical analysis and drafted the paper. B. E. Wama, T. D. Hile, and J. B. Bingbeng collected data and carried out laboratory analyses. L. C. Garba and S. O. Elkanah were involved in literature searches and data collection. S. L. Kela and E. U. Amuta critically revised the paper. All authors read and approved the paper.

\section{Acknowledgments}

The authors are grateful to all the pregnant women that consented to participate in this research without whom blood sample for examinations would not have been feasible. They are much indebted to Mr. Sunday Ochayi, Quality Officer, who ran haematological parameters from the Centre for Integrated Health Programs (CIHP) laboratory incorporated within the General Hospital Vandeikya. The management of the General Hospital, Vandeikya, is thankfully acknowledged for granting us permission to undertake this research.

\section{References}

[1] WHO, "Malaria and HIV/AIDS interactions and implications. Conclusions of a Technical Consultation convened by WHO," 2004, http://www.emro.who.int/aiecf/web26.pdf.

[2] R. W. Steketee, B. L. Nahlen, M. E. Parise, and C. Menendez, "The burden of malaria in pregnancy in malaria-endemic areas," American Journal of Tropical Medicine and Hygiene, vol. 64, no. 1-2, pp. 28-35, 2001.

[3] F. O. Ter Kuile, M. E. Parise, F. H. Verhoeff et al., "The burden of co-infection with human immunodeficiency virus type 1 and malaria in pregnant women in sub-Saharan Africa," The American Journal of Tropical Medicine and Hygiene, vol. 71, no. 2, pp. 41-54, 2004.

[4] S. D. Perrault, J. Hajek, K. Zhong et al., "Human immunodeficiency virus co-infection increases placental parasite density and transplacental malaria transmission in western Kenya," The American Journal of Tropical Medicine and Hygiene, vol. 80, no. 1, pp. 119-125, 2009.

[5] A. M. van Eijk, J. G. Ayisi, F. O. Ter Kuile et al., "HIV increases the risk of malaria in women of all gravidities in Kisumu, Kenya," AIDS, vol. 17, no. 4, pp. 595-603, 2003.

[6] F. H. Verhoeff, B. J. Brabin, C. A. Hart, L. Chimsuku, P. Kazembe, and R. L. Broadhead, "Increased prevalence of malaria in HIV-infected pregnant women and its implications for malaria control," Tropical Medicine and International Health, vol. 4, no. 1, pp. 5-12, 1999.

[7] Global Report, "UNAIDS report on the global AIDS epidemic," 2010.

[8] "Nigeria Malaria Fact Sheet," http://nigeria.usembassy.gov.

[9] R. S. Houmsou, E. U. Amuta, and T. T. Sar, "Malaria prevention during pregnancy: awareness and factors contributing to disease occurrence among pregnant women in Gboko metropolis," Journal of Medicine and Biomedical Sciences, vol. 2, no. 3, pp. 36-40, 2010.

[10] R. S. Houmsou, E. U. Amuta, T. T. Sar, and A. A. Adie, "Malarial infection in pregnant women attending antenatal clinics in Gboko, Benue State, Nigeria," International Journal of Academic Research, vol. 2, no. 1, pp. 33-36, 2010.

[11] R. S. Houmsou, E. U. Amuta, B. E. Wama, T. D. Hile, and J. B. Bingbeng, "Occurrence of malaria in children under five years: knowledge, attitudes and perceptions among mothers in a semiurban area of Benue State, Nigeria," Journal of Scientific Research \& Reports, vol. 3, no. 8, pp. 1127-1134, 2014.

[12] E. U. Amuta, R. S. Houmsou, E. Wama, and M. Ameh, "Malarial infection among antenatal and maternity clinics attendees at 
the Federal Medical Centre, Makurdi, Benue State, Nigeria," Infectious Disease Reports, vol. 6, no. 1, p. 5050, 2014.

[13] Centre for Integrated Health Programs, http://www.cihpng .org/.

[14] M. Cheesbrough, Medical Laboratory Manual for Countries Part 2, Cambridge University Press, Cambridge, UK, 2nd edition, 2000.

[15] WHO, "Haemoglobin concentrations for the diagnosis of anaemia and assessment severity," in Micronutrients Indicators: Vitamin A and Mineral Nutrition Information System, World Health Organization, Geneva, Switzerland, 2011.

[16] A. O. Sanyaolu, A. F. Fagbenro-Beyioku, W. A. Oyibo, O. S. Badaru, O. S. Onyeabor, and C. I. Nnaemeka, "Malaria and HIV co-infection and their effect on haemoglobin levels from three healthcare institutions in Lagos, southwest Nigeria," African Health Sciences, vol. 13, no. 2, pp. 295-300, 2013.

[17] A. P. Kapito-Tembo, Malaria and anemia in HIV-infected pregnant women in Malawi: associations with cotrimoxazole prophylaxis, submicroscopic malaria, iron supplementation and iron deficiency [Ph.D. thesis], University of North Carolina, 2010.

[18] J. Ladner, V. Leroy, A. Simonon et al., "HIV infection, malaria, and pregnancy: a prospective cohort study in Kigali, Rwanda," The American Journal of Tropical Medicine and Hygiene, vol. 66, no. 1, pp. 56-60, 2002.

[19] R. W. Steketee, J. J. Wirima, P. B. Bloland et al., "Impairment of a pregnant woman's acquired ability to limit Plasmodium falciparum by infection with human immunodeficiency virus type-1," The American Journal of Tropical Medicine and Hygiene, vol. 55, supplement, no. 1, pp. 42-49, 1996.

[20] A. M. Mount, V. Mwapasa, S. R. Elliott et al., "Impairment of humoral immunity to Plasmodium falciparum malaria in pregnancy by HIV infection," The Lancet, vol. 363, no. 9424, pp. 1860-1867, 2004.

[21] E. U. Amuta, R. S. Houmsou, and A. W. Diya, "Malarial infection among HIV patients on antiretroviral therapy (ART) and not on ART: a case study of Federal Medical Centre Makurdi, Benue State, Nigeria," Asian Pacific Journal of Tropical Disease, vol. 2, no. 1, pp. S378-S381, 2012.

[22] R. Kasirye, J. Levin, P. Munderi et al., "Epidemiology of malaria in HIV infected Ugandan patients on antiretroviral therapy (ART) - a prospective cohort study," in Proceedings of the 5th IAS Conference on HIV Pathogenesis, Treatment and Prevention, Cape Town, South Africa, July 2009.

[23] T. S. Skinner-Adams, J. S. McCarthy, D. L. Gardiner, and K. T. Andrews, "HIV and malaria co-infection: interactions and consequences of chemotherapy," Trends in Parasitology, vol. 24, no. 6, pp. 264-271, 2008. 


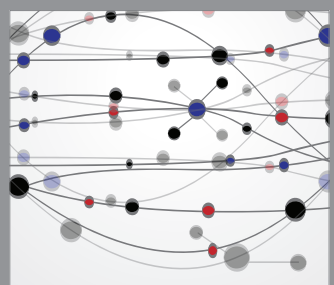

The Scientific World Journal
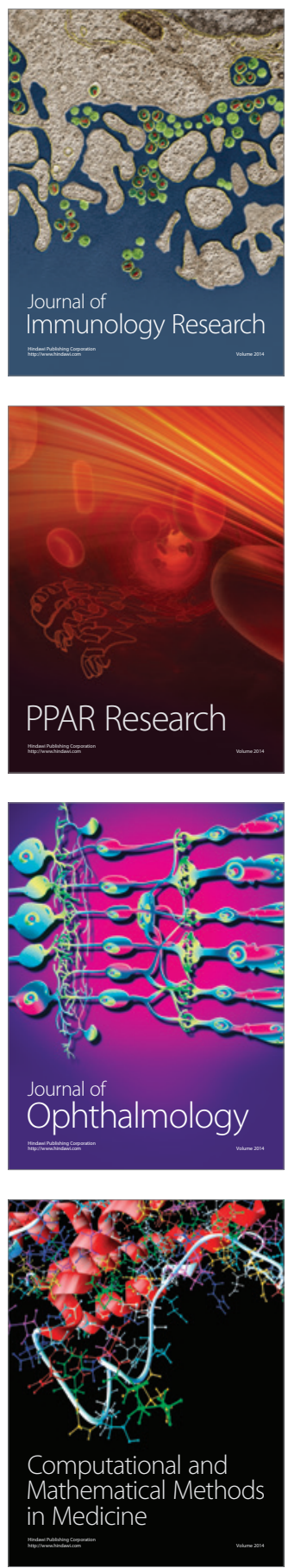

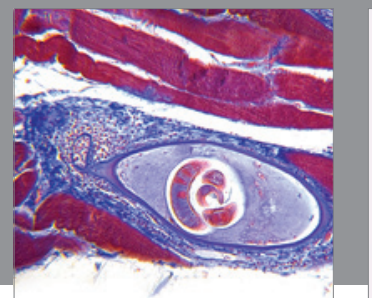

Gastroenterology

Research and Practice
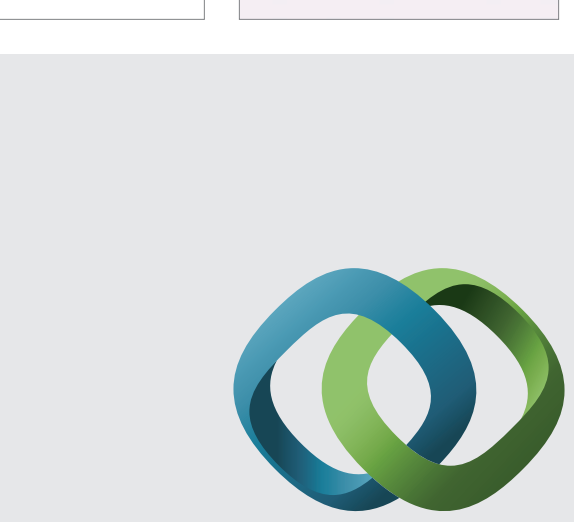

\section{Hindawi}

Submit your manuscripts at

http://www.hindawi.com
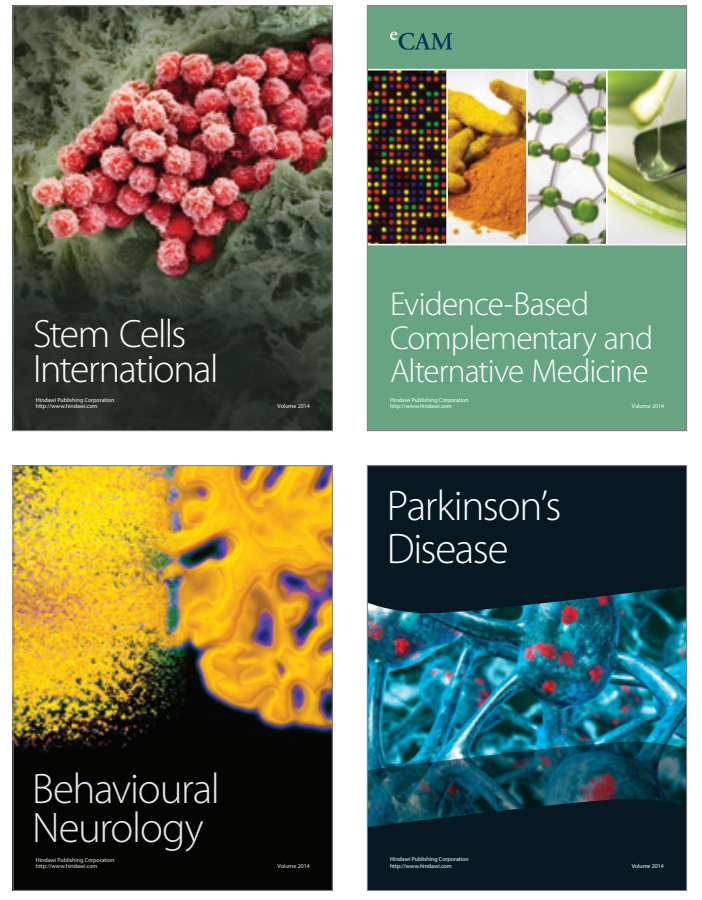
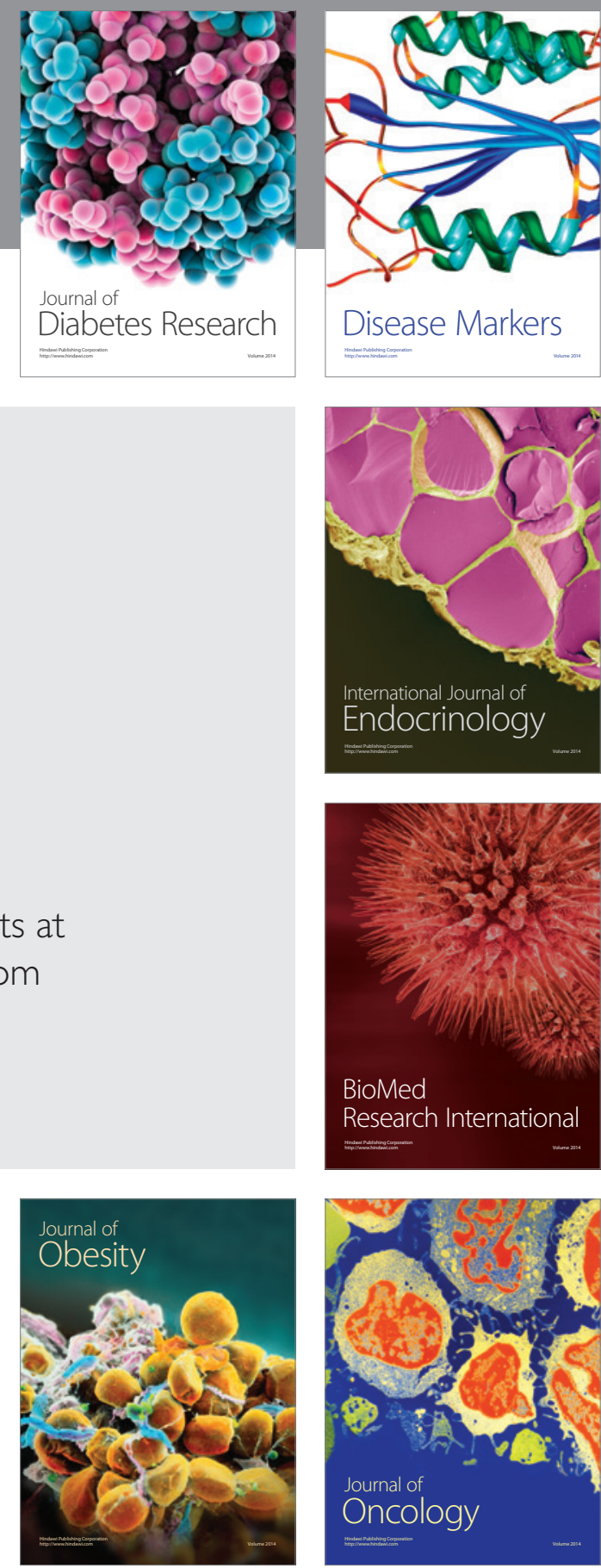

Disease Markers
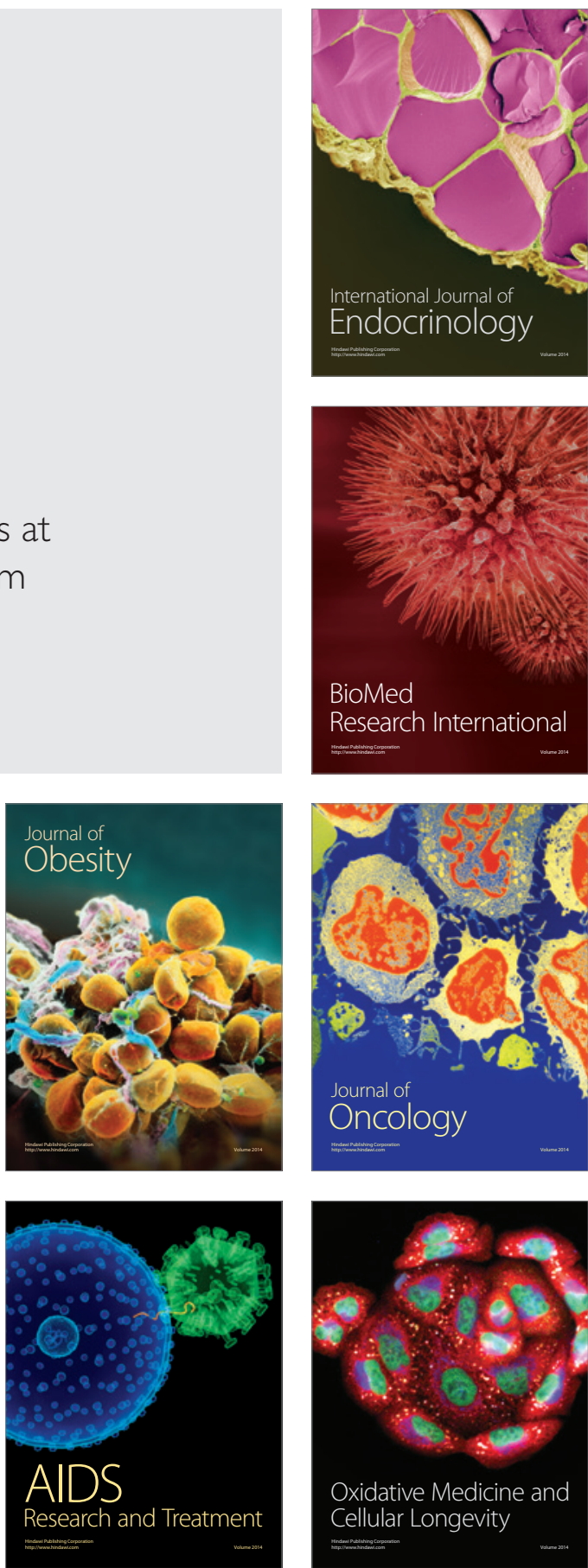